\title{
Growth of undoped and metal doped ZnO nanostructures by solution growth
}

\author{
Rathinam Chandramohan, Thirukonda Anandamoorthy Vijayan \\ and Jagannathan Thirumalai \\ Department of Physics,Sree Sevugan Annamalai College,Devakottai - 630303 \\ India
}

\section{Introduction}

$\mathrm{ZnO}$ is one of the most studied materials of the II-VI oxide materials that derive continuous attention of the researchers worldwide since forties (Bunn 1935). Because of its current and possible applications in several novel devices, renewed interest has emerged and several reviews (Liu et al, 2005; Tsukazaki et al, 2005), and conference proceedings are published exclusively for $\mathrm{ZnO}$ nano crystallites similar systems at Singapore (2005), (2009) and Changchan, China (2006) to explore the feasibility of commercial application for future devices. Yet the ream of novel devices from this wonderful material is yet to be accomplished in full (Wellings, et al, 2008). With a wide band gap of $3.2 \mathrm{eV}$ and a large exciton binding energy of $60 \mathrm{meV}$ at room temperature, $\mathrm{ZnO}$, line $\mathrm{GaN}$, will be important for blue and ultraviolent optical devices. $\mathrm{ZnO}$ has several advantages over $\mathrm{GaN}$ in this applications range however, the most important being its longer exciton binding energy and the ability to grow single crystal substrates. Other favourable aspects of $\mathrm{ZnO}$ include its broad chemistry leading to many opportunities for wet chemical etching, low power threshold for optical pumping, radiation hardness and biocompatibility. Together, these properties of $\mathrm{ZnO}$ make it an ideal candidate for a variety of devices ranging from sensors through to ultra-violet laser devices and nanotechnology based devices such as displays. As fervent research into $\mathrm{ZnO}$ continues, difficulties such as the fabrication of p-type $\mathrm{ZnO}$ that have so far stated that the development of devices had over come (Yang etal, 2008). To give a quantitative report on the state of art of $\mathrm{ZnO}$ nanocrystals is quite difficult and an attempt has been made to survey the chemical growth of this system in this study. The chemical solution growth of $\mathrm{ZnO}$ nano thin films composed of nano crystallites using a two step double dip chemical deposition method has been discussed In detail in this chapter. The growth and characterization of nano structures of $\mathrm{ZnO}$ has been reported by Wang (Wang, 2004).

Mitra et al (1998) has prepared Zinc Oxide thin films using chemical deposition technique. The structural, morphological properties of the prepared films are characterized using X-ray diffraction and scanning electron microscope. They have used $\mathrm{Zn}$ salts as precursor and successfully synthesized $\mathrm{ZnO}$ films. The growth of highly textured Zinc oxide $(\mathrm{ZnO})$ thin films with a preferred (101) orientation has been prepared by employing chemical bath 
deposition using a sodium zincate bath on glass substrates has been reported by (Ramamoorthy et al, 2004). The films were characterized by XRD, SEM, EDX, UV-Vis-NIR, FTIR and PL in order to justify the suitability for commercial device quality. (Natsume et al, 2000) have studied the d.c electrical conductivity and optical properties of zinc oxide film prepared by a sol-gel spin coating technique. The temperature dependence of the conductivity indicated that electron transport in the conduction band was due to thermal execution of donor electrons for temperatures from 250 to $300 \mathrm{~K}$. (Chapparro et al, 2003) have proposed the spontaneous growth of $\mathrm{ZnO}$ thin films from aqueous solutions. An electroless - chemical process is proposed, consisting in the formation of the super oxide radical $\left(\mathrm{O}_{2}-\right)$ followed by chemical reaction of two $\mathrm{O}_{2}{ }^{-}$with $\mathrm{Zn}\left(\mathrm{NH}_{3}\right)_{4}{ }^{2+}$ cations. (Wellings et al, 2008) have deposited $\mathrm{ZnO}$ thin films from aqueous zinc nitrate solution at $80^{\circ} \mathrm{C}$ onto fluorine doped tin oxide (FTO) coated glass substrates. Structural analysis, surface morphology, optical studies and electrical conductivity were studied and thickness of the $\mathrm{ZnO}$ films was found to be $0.40 \mu \mathrm{m}$. (Walter Walter et al, 2007) have studied the characterization of strontium doped $\mathrm{ZnO}$ thin films on love wave filter applications. X-ray diffraction, scanning electron microscopy and atomic force microscopy studied the crystalline structure and surface morphology of films. The electrochemical coupling coefficient, dielectric constant, and temperature coefficient of frequency of filters were then determined using a network analyzer. (Vijayan et al, 2008, a, b) have reported the preparation conditions for undoped $\mathrm{ZnO}$ using double dip technique and used them for gas sensor applications. They have also reported the synthesis of $\mathrm{Sr}$ doped $\mathrm{ZnO}$ using double dip technique and used them for gas sensor applications. Recently (Chandramohan et al, 2010) have synthesized $\mathrm{Mg}$ doped $\mathrm{ZnO}$ thin films using double dip chemical growth and reported the ferromagnetic properties of the films. Tahir Saeed et al. (1995) have deposited thin films of mono phase crystalline hexagonal $\mathrm{ZnO}$ from solutions of zinc acetate in the presence of ethylenediamine and sodium hydroxide on to glass microscope studies. Two distinct morphologies of $\mathrm{ZnO}$ were observed by scanning electron microscopy. The deposited films were specular and adherent. (Cheng et al 2006) have fabricated thin films transistors (TFTs) with active channel layers of zinc oxide using a low - temperature chemical bath deposition. Current voltage (I-V) properties measured through the gate reveal that the $\mathrm{ZnO}$ channel is n-type. (Sadrnezhaad et al 2006) have studied the effect of addition of Tiron as a surfactant on the microstructure of chemically deposited zinc oxide. Addition of tiron charges the surface morphology and causes to form the fine - grained structure. The obtained results indicate that increasing the number of dipping carves to progress the deposition process. (Piticescu, et al 2007) have studied the influence of the synthesis parameters on the chemical and microstructural characteristics of nanophases synthesized in the two methods. 'Al' doping tends to a lower material density and to a smaller gown size. Zhou et al (2007) have studied microstructure electrical and optical properties of aluminium doped zinc oxide films. The ZnO:Al thin films are transparent $(\sim 90 \%)$ in near ultraviolet and visible region $\mathrm{A}$. with the annealing temperature increasing from $300^{\circ} \mathrm{C}$ to $500^{\circ} \mathrm{C}$. The film was oriented more preferentially along the (002) direction, the grain size of the film increased, the transmittance also became higher and the electrical resistivity decreased. Joseph et al (2006) have reported the structural, electrical and optical properties of Al-doped $\mathrm{ZnO}$ thin films prepared by chemical spray deposition. XRD studies and SEM studies revealed that the film was polycrystalline in nature with (002) preferred concentration and smooth conditions have exhibited a resistivity of $2.45 \times 10^{-4} \Omega \mathrm{m}$ with an 
optical transmittance of $97 \%$ of $550 \mathrm{~nm}$. Oral et al (2007) have studied microstructure and optical properties of monocrystalline $\mathrm{ZnO}$ and $\mathrm{ZnO}: \mathrm{Li} / \mathrm{Al}$ thin films. Crystallized films had a grain size under $50 \mathrm{~nm}$ and showed C-axis grain orientation. All films had a very smooth surface with RMS and surface roughness values between 0.23 and $0.35 \mathrm{~nm}$. Peiro et al (2005) have reported microwave-activated chemical bath depositions of zinc oxide thin films. Scanning electron microscopic characterization suggested that both the shape of the crystals and the textures of the film were highly influenced by the chemical path composition. Composition of films grown on bone glass or fluorine - doped tin oxide $\left(\mathrm{SnO}_{2}\right.$ : F) showed that heterogeneous deposition was favoured on conducting substrates due to the localized heating. Bulk $\mathrm{ZnO}$ is quite expensive and unavailable in large wafers. So, for the time being, thin films of $\mathrm{ZnO}$ are relatively a good choice. Usually, the doped $\mathrm{ZnO}$ films with optimum properties (perfect crystalline structure, good conducting properties, high transparency, high intensity of luminescence) are obtained when they are grown on heated substrates and annealed after deposition at high temperature in oxygen atmosphere (Peiro et al, 2005 Lokhande et al, 2000; Srinivasan et al, 2006; Chou et al, 2005). However, for an extensive use in the commercial applications pure and doped $\mathrm{ZnO}$ films must be prepared at much lower substrate temperatures. Therefore, it is necessary to develop a lowtemperature deposition technology for the growth of $\mathrm{ZnO}$ films. Many works are seen in the low temperature growth of this interesting $\mathrm{ZnO}$ system both undoped and metal doped (Tang et al, 1998, Cracium et al, 1994; Gorla et al, 1999; Kotlyarchuk et al, 2005) thin films and nano thin films. Advantages are effectiveness and simplicity of the deposition equipment, high deposition rates, wide spectrum of deposition parameters for the control and the optimization of film properties, and film thickness. The sum of all these special features enables the growth of oxide thin films at low temperature substrates with perfect crystallinity. The present work is a preparation and characterization of undoped $\mathrm{ZnO}, \mathrm{Sr}-$ doped $\mathrm{ZnO}(\mathrm{SZO})$ and $\mathrm{Al}-$ doped $\mathrm{ZnO}(\mathrm{AZO})$ thin films by chemical deposition technique. In which the influence of solution concentration, solution $\mathrm{pH}$ value, film thickness, annealing temperature and concentration of strontium and aluminium atoms of the grown films are investigated. In addition it demonstrates that any dopant can be used in principle along with the precursor to enable them to be included in the system. The technique can be tuned to get the desired morphology and nanocrystallites of desired sizes distributed over any type of substrate for various applications.

\section{Substrate and its preparation}

Thin film requires a substrate to support itself. The substrate provides the necessary mechanical strength and rigidity needed for the film and it has adequate thermal ability to ensure at room temperature and withstand at high temperature. The function of the substrate is to provide the base on to which the thin film circuits are fabricated and various thin film multilayers are deposited. To form the thin film with defined electrical parameters, the substrates must be smooth and flat otherwise electrical and optical properties may be affected. Therefore in choosing a suitable substrate, in addition to considering the need to provide the mechanical support to the deposits, due consideration must be given to the possible influence of the substrates on the properties of the deposits. Commonly used substrate materials for polycrystalline thin film circuits include alumina, glass, silicon and metals, beryllium oxide based ceramic, aluminium nitride. When the films are deposited 
into glass, electrical and optical measurements are not disturbed by an underlying layer and are thus easier to interpret. Of all these, glass is found to posses all the requirements and is economically and widely used. However any type of substrate may be used in this simple growth method. Substrate cleaning in thin film technology is an important step prior to deposition. It is necessary to remove the contaminants that would otherwise affect the properties of the film. Cleaning involves the removal of contaminants without damage to the substrate. While cleaning, the bond between the substrates is broken and contaminants are set free from the substrates. The properties that can be affected by the presence of contaminants include morphology, nucleation electronic properties and the substrate film interface. Expected contaminants include fingerprints, dust, oil, and lint particles. The proper cleaning technique depends on the nature of the substrate and nature of the contaminants. The composition, physical properties such as porosity, thermal expansion, melting point, conductivity and chemistry of the substrate should be carefully considered in designing the cleaning operation. The energy required to break those bond could be supported by chemical, salvation, thermal (or) mechanical process. As the other techniques this technique also involves rigorous cleaning of the substrates.

\section{Growth of nanocrystallites of undoped and doped ZnO}

\section{Experimental}

A schematic diagram of the shape-selective synthesis of doped and undoped metal oxide nanostructures via double dip technique is shown in Fig. 1. Preparation of undoped and doped $\mathrm{ZnO}$ nano thin films $\mathrm{ZnO}$ thin films were performed using a two-step chemical bath deposition technique using a solution comprising of high purity zinc sulphate, magnesium sulphate and sodium hydroxide with a $\mathrm{pH}$ value of 9 as first step and a dip in hot water kept near boiling point as the second step. Before deposition, the glass substrates were cleaned by chromic acid followed by cleaning with acetone. The well-cleaned substrates were immersed in the chemical bath for a known standardized time followed by immersion in hot water for the same time for hydrogenation.

\section{Possible formation mechanism}

The process of solution dip (step 1) followed by hot water dipping (step 2) is repeated for known number of times. According to the following equation, the complex layer deposited on the substrate during the dipping in sodium zincate bath will be decomposed to $\mathrm{ZnO}$ due to subsequent dipping in hot water. The proposed reaction mechanism for undoped $\mathrm{ZnO}$ is according to the following equations

$$
\begin{aligned}
& \mathrm{ZnSO}_{4}+2 \mathrm{NaOH} \rightarrow \mathrm{Na}_{2} \mathrm{ZnO}_{2}+\mathrm{H}_{2} \mathrm{SO}_{4} \uparrow \ldots . . \\
& \mathrm{Na}_{2} \mathrm{ZnO}_{2}+\mathrm{H}_{2} \mathrm{O} \rightarrow \mathrm{ZnO}+2 \mathrm{NaOH} \ldots \ldots . .
\end{aligned}
$$

Part of the $\mathrm{ZnO}$ so formed was deposited onto the substrate as a strongly adherent film and the remainder formed as a precipitate. The addition of Metal sulphate in the ratio of $\mathrm{Zn}$ : Metal as 100:1 in the first dip solution leads to the formation of MZO films.

$\mathrm{ZnO}$ thin films were prepared using double dip technique shown in Fig. 1 by varying deposition parameters such as solvent medium, solution $\mathrm{pH}$, concentrations, temperature, 
number of dippings, etc., The effect of these parameters are studied using various characterizations and the optimized deposition parameters are arrived for undoped $\mathrm{ZnO}$ thin films. The ' $\mathrm{Al}$ ' and ' $\mathrm{Sr}$ ' doping were carried out by adding the respective metallc salts in the solution bath at different proportions $\left(\mathrm{Zn}: \mathrm{M}\right.$ as $100: 1$ or $10: 1$ where $\mathrm{M}={ }^{\prime} \mathrm{Sr}^{\prime}$ or ' ${ }^{A} l^{\prime}$.

\section{Water bath}

\section{Sodium Zincate bath}

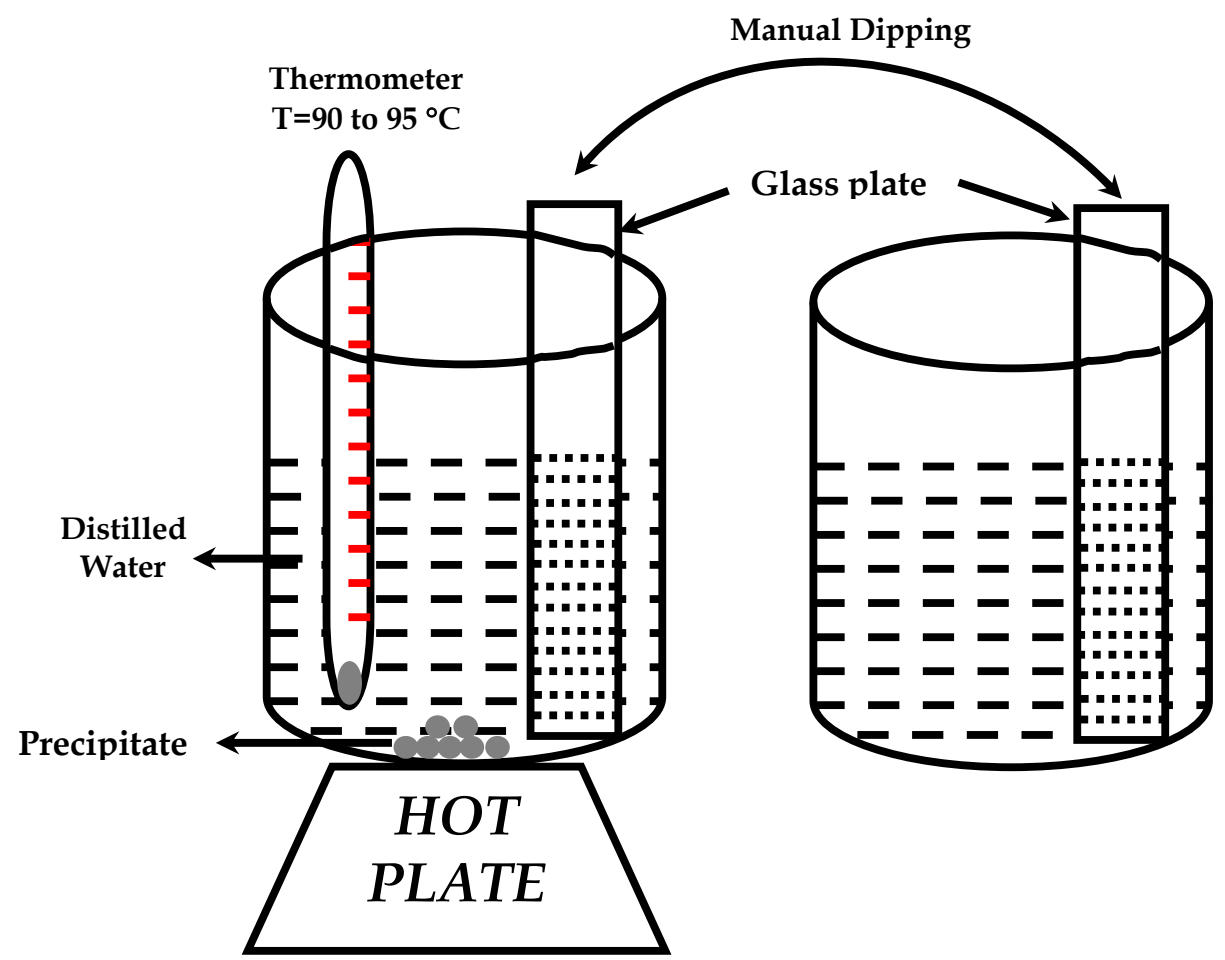

Fig. 1. Schematic representation of solution dip technique

\section{Opimization of growth conditions}

Undoped, Strontium doped $\mathrm{ZnO}$ (SZO) and Aluminium doped $\mathrm{ZnO}$ (AZO) thin films are prepared by solution grown double dip technique. The films are annealed in air to improve the crystallinity and grain sizes. All the synthesized films are characterized for their structural, optical, surface morphology, surface roughness, compositional analysis, X-ray photoemission spectroscopy analysis and electrical properties. The doping of Strontium and Aluminium $(0.1 \mathrm{mM}$ and $1 \mathrm{mM})$ concentration thin films by solution grown double dip technique is performed and investigated. The salient features of various studies carried out and the important findings are presented in this chapter. Zinc Oxide and doped ( $\mathrm{Sr}$ and $\mathrm{Al}$ ) thin films find interesting applications in the filed of gas sensor, solar cells, optoelectronic 
devices etc., Aluminium doped Zinc Oxide thin films are more suitable for gas sensor applications owing to their band gap and stability. This chapter describes widely the synthesis $\mathrm{ZnO}$, Sr-doped $\mathrm{ZnO}(\mathrm{SZO})$ and $\mathrm{Al}$-doped $\mathrm{ZnO}(\mathrm{AZO})$ thin films by solution grown double dip technique from aqueous solutions of $\mathrm{ZnSO}_{4}$. The films prepared are found to be compact and homogeneous. The deposition conditions are optimized to obtain uniform, thin films suitable for gas sensor applications. The optimized deposition conditions to prepare $\mathrm{ZnO}$ films are

Bath composition and deposition conditions

$\begin{array}{ll}\text { Zinc Sulphate } & : 0.1 \mathrm{M} \\ \text { Sodium hydroxide } & : 0.2 \mathrm{M} \\ \text { Solution pH } & : 9 \pm 0.2 \\ \text { Bath temperature } & : 90^{\circ} \mathrm{C}\end{array}$

SZO and AZO thin films are prepared at various molarities $(0.1 \mathrm{mM}$ and $1 \mathrm{mM})$ under optimized condition to obtain uniform, thin film suitable for gas sensor applications. The optimized deposition conditions to prepare SZO and AZO thin films are

Bath composition and deposition conditions

Strontium doped Zinc oxide (SZO) thin films

$\begin{array}{ll}\text { Zinc sulphate } & : 0.1 \mathrm{M} \\ \text { Sodium hydroxide } & : 0.2 \mathrm{M} \\ \text { Strontium Sulphate } & : 0.1 \mathrm{mM} \text { and } 1 \mathrm{mM} \\ \text { Solution } \mathrm{pH} & : 9 \pm 0.2 \\ \text { Hot water temperature } & : 90^{\circ} \mathrm{C} \\ \text { Aluminium doped Zinc Oxide (AZO) } & \text { thin films } \\ \text { Zinc sulphate } & : 0.1 \mathrm{M} \\ \text { Sodium hydroxide } & : 0.2 \mathrm{M} \\ \text { Aluminium Sulphate } & : 0.1 \mathrm{mM} \text { and } 1 \mathrm{mM} \\ \text { Solution pH } & : 9 \pm 0.2 \\ \text { Hot water temperature } & : 90^{\circ} \mathrm{C}\end{array}$

The growth conditions have been optimized by us for various dopants including non metals. Several parameters involved in this technique offer wide range of selection of parameters. It is found that the films deposited at room temperature are found to be smooth and uniform and compatible with any physical or chemical techniques.

\section{The structure and morphology of the nanostructures}

To support the discussion on the optimization of growth conditions the SEM studies were carried out. The studies reveal that by altering the deposition conditions morphologies with minor variations can be obtained. Figure 2-4 shows the SEM micrographs of $\mathrm{ZnO}$ grown using double dip technique where 40,80 and 100 respectively. 
It is observed that improving the number of dipping yields the better morphology films. It is observed that the film is quite uniform up to a thickness in the range of few microns with the variation in the range of $10 \mathrm{~nm}$. While the grains of the film surfaces are uniformly in the average range of $300 \mathrm{~nm}$, the surface seems to be formed by the stacking of different nanorods or cylindrical grains whose size varied from 20 to $500 \mathrm{~nm}$.

To support the discussion on the optimization of growth conditons the AFM studies were carried out. The studies reveal that by altering the deposition conditions morphologies with minor varitions can be obtained. Figures $5(\mathrm{a}-\mathrm{c})$ represents 3D AFM micrographs obtained for $\mathrm{ZnO}$ samples grown at room temperature under optimized conditions. It is observed that the stacking of different nanorods or tubular grains whose size varied from 20 to 500 $\mathrm{nm}$ makes the samples topography. Adjusting the deposition parameters may control the size of the grains. It is interesting that the morphology when further explored using $2 \mathrm{D}$ and 3D analysis supported by SEM investigations that morphology is also due to the nearly spherical nano grains.

Adjusting the deposition parameters gives a control on the growth of nanocrystallites with various sizes and shapes. It is interesting to know that the dip rate, interval between successive dippings, the variations in second dip bath, etc produces significant changes in the morphology inviting more number of researchers in this low cost nanocrystallites growth. For doping with other metals respective salts may be replaced in the place of aluminum sulphate. This method of growth facilitates fabricating excellent structures for future devices at low cost and low temperature. The technique is found to be highly reproducible and can be extended to large area and large scale fabrication systems.

In summary, the synthesis and optimization of undoped and doped $\mathrm{ZnO}$ systems have been reported. The Morphological studies through AFM and SEM reveal's excellent features associated with nanocrystallites of which the structure is made. The SEM reveals continuously stacked nanorods of diameter ranging from $20 \mathrm{~nm}$ to few hundred nanometers. The AFM studies reveal the surface to be of minimum roughness composed of spherical and hexagonal shaped grains. They are uniformly distributed throughout the surface exhibiting the superiority of the films. Extensive characterizations on the structure, microstructure optical and electrical properties have been made and the exotic choice available in this simple method has paved way for the synthesis of many similar systems by our group like $\mathrm{Fe}, \mathrm{Mg}$ and $\mathrm{Mn}$ doped $\mathrm{ZnO}$ thin films and other TCO systems like CdO, etc. Also the properties of these thin film nanocrystallites can be tailored to suit variety of applications like, phosphors, display panels, thermal conduction and opto electronic devices. The technique is easy for automation and anticorrosive coatings can be coated employing doped $\mathrm{ZnO}$ systems on to various mechanical spares. The potential of this technique is yet to be exploited in full by the industrial community. The crystallite shape and size control is also feasible in this excellent method. 
(a)

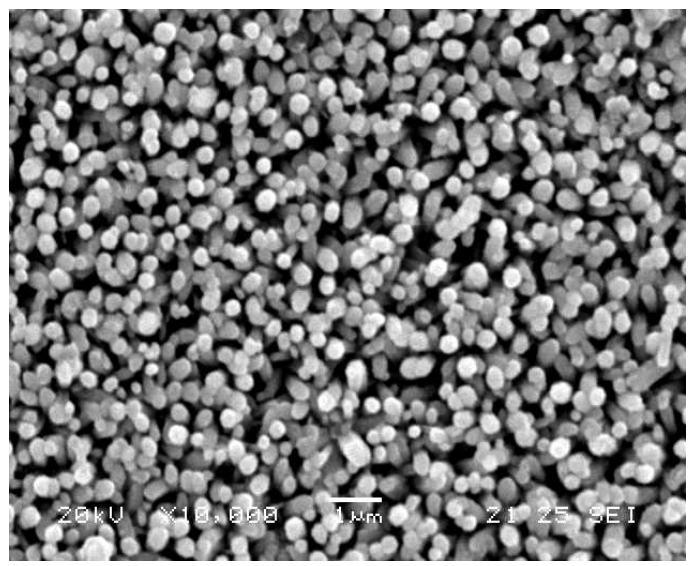

(b)

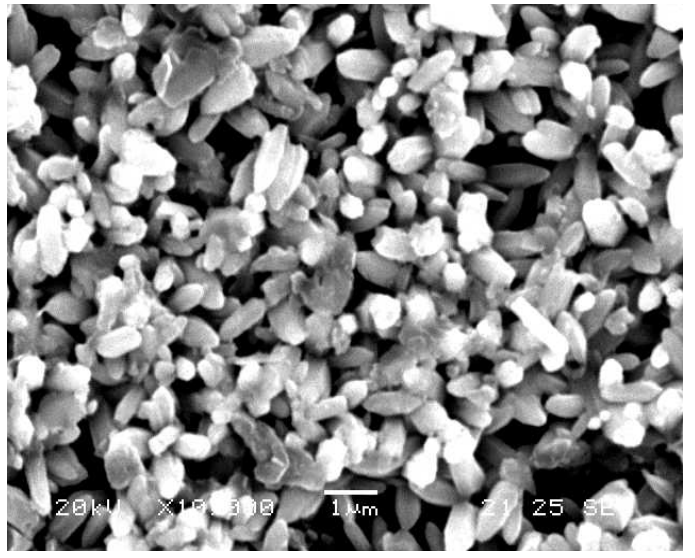

(c)

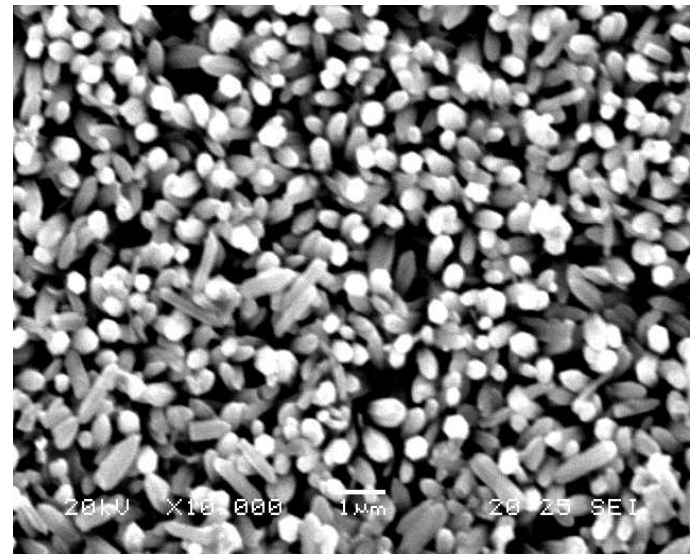

Fig. 2. Surface morphology on (a) $\mathrm{pH}=8$, (b) $\mathrm{pH}=9$ and (c) $\mathrm{pH}=10$ of $\mathrm{ZnO}$ thin films. 
(a)

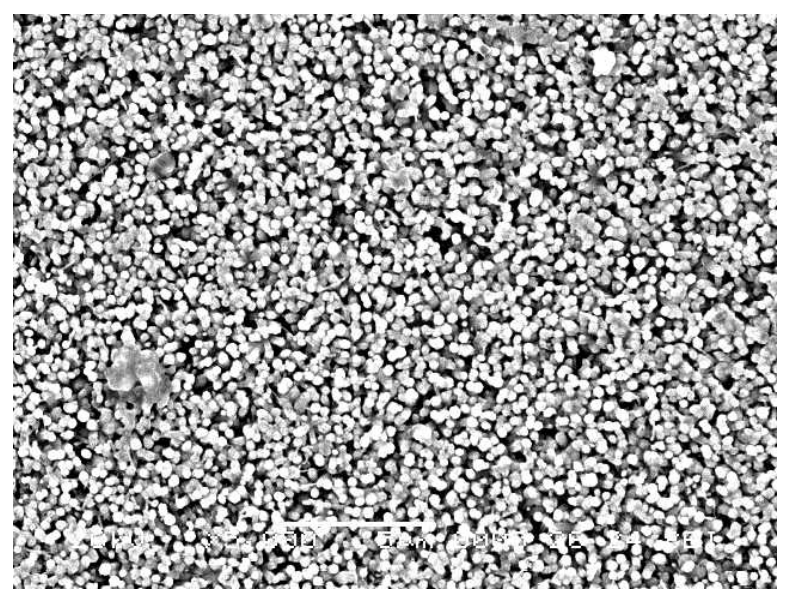

(b)

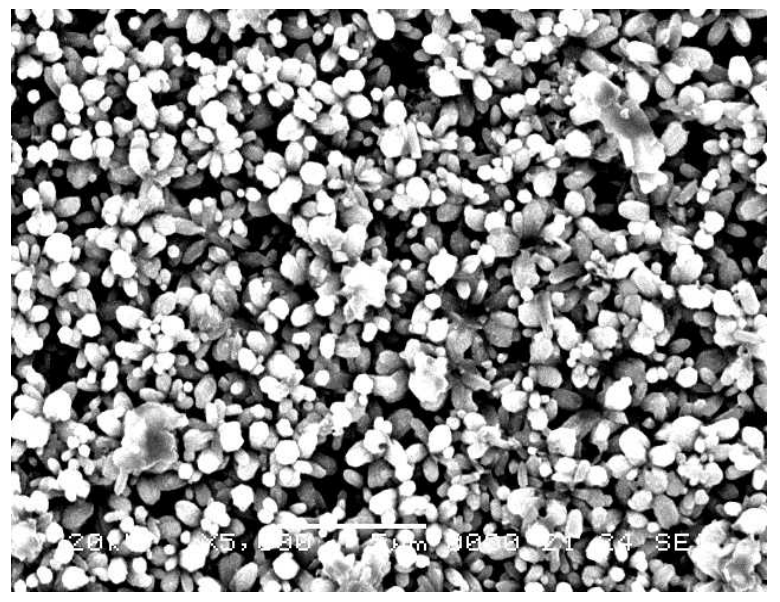

Fig. 3. Surface morphology on (a) Al-doped (0.1mM), (b) Al-doped (1mM) ZnO thin films. 
(a)

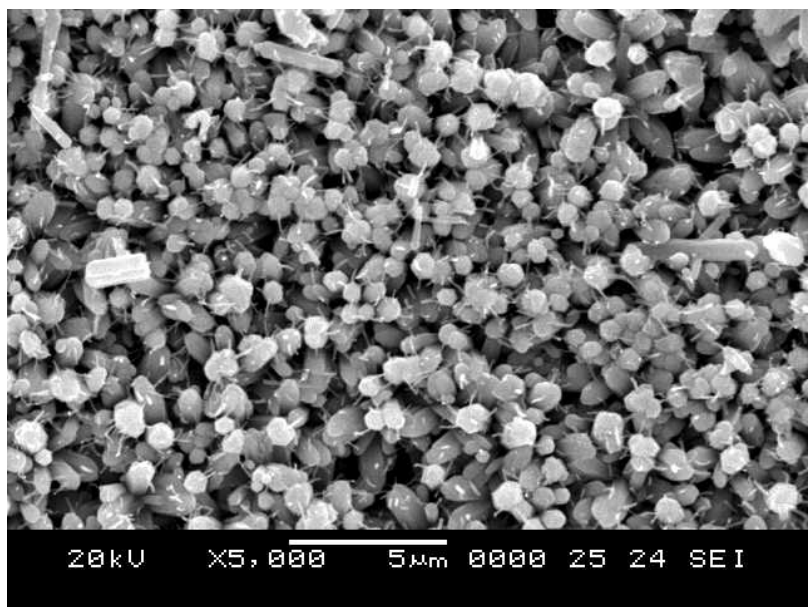

(b)

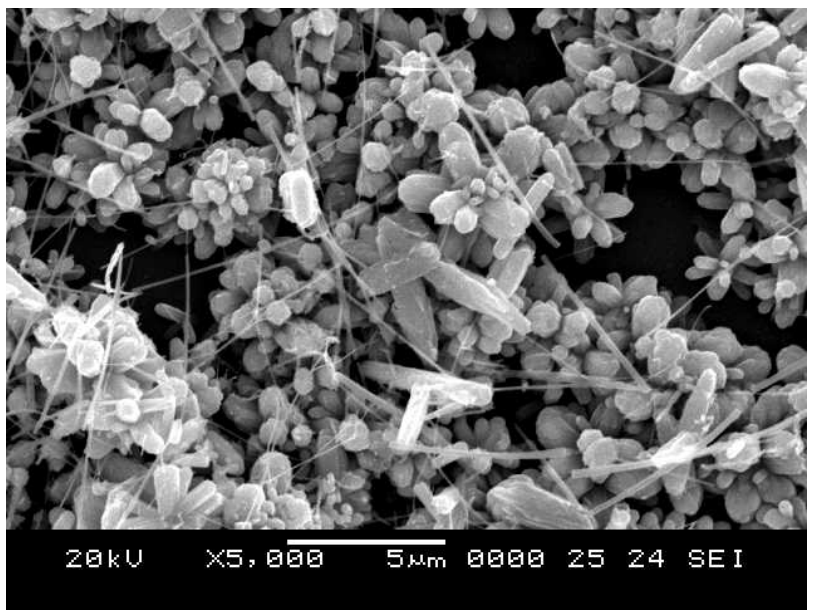

Fig. 4. Surface morphology on (a) Sr-doped (0.1mM), (b) Sr-doped (1mM) ZnO thin films. 
(a)

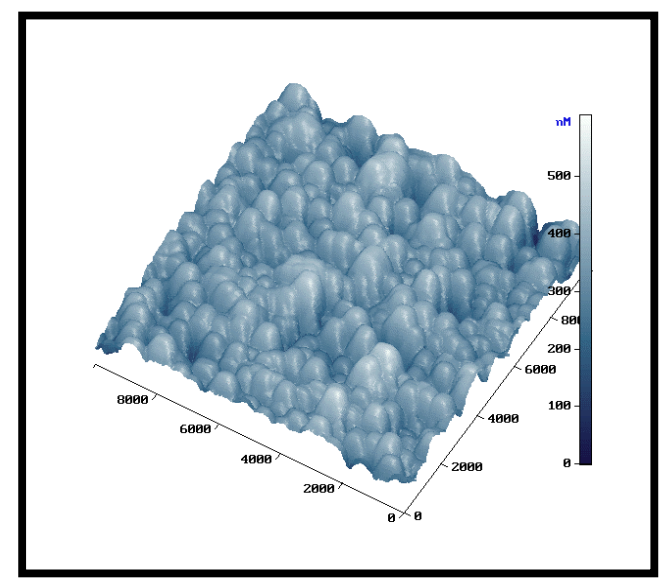

(b)

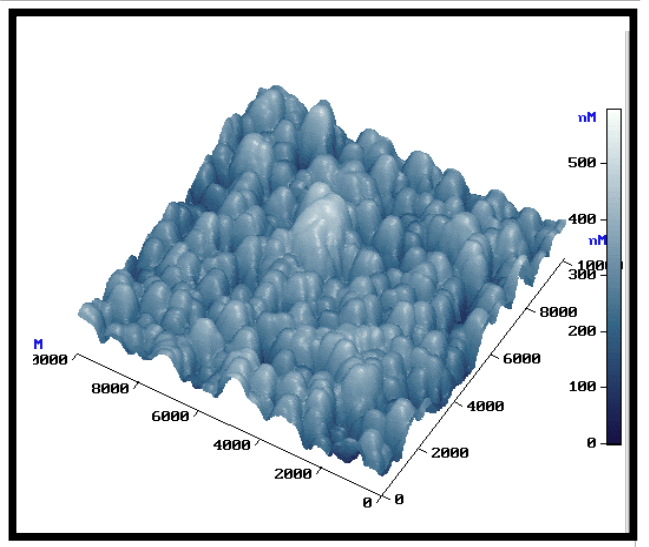

(c)

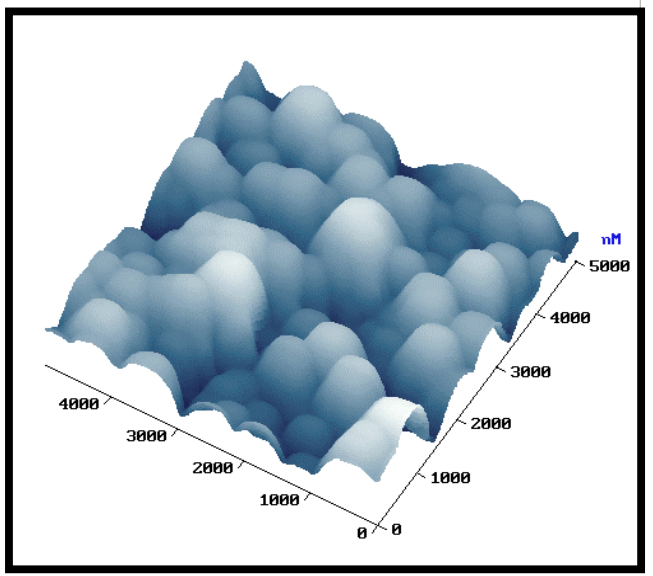

Fig. 5. (a-c) Shows 3D AFM micrographs obtained for $\mathrm{ZnO}, \mathrm{SZO}$ and $\mathrm{AZO}$ samples grown at room temperature under optimized conditions. 


\section{References}

Bunn, C.W. (1935). The lattice-dimensions of zinc oxide. Proc. Phys. Soc. London., 47., 5., 835842, ISSN 0959-5309.

Liu, C.; Yun, F.; \& Morkoç, H, (2005). Ferromagnetism of ZnO and GaN: A Review J. Mater. Sci: Mat in Electronics. 16., 9., 555-597, ISSN: 0957-4522.

Tsukazaki, A.; Ortomo, A.; Onuma, T.; Ohtani, M. \& Makino, T.; Smiya, M.; Ohtani, K.; Chichibu, S.F.; Fuke, S.; Egawa, Y.S.; Ohno, H.; Kainuma, K. \& Kawasaki, M. (2005). Repeated temperature modulation epitaxy for p-type doping and light-emitting diode based on ZnO. Nat. Mater., 4., 1., (December 2004) 42-46, ISSN: 1476-1122.

Özgür, Ü.; Alivov, Ya. I.; Liu, C.; Teke, A.; Reshchikov, M.A.; Doğan, S.; Avrutin, V.; Cho, S.J. \& Morkoç, H. (2005). A comprehensive review of $\mathrm{ZnO}$ materials and devices. J. Appl. Phys.98., 4., (August 2005) 041301-041404, ISSN 0021-8979.

Wang, Z.L. (2004). Zinc oxide nanostructures: growth, properties and applications. J.Phys.: Cond. Matter., 16., 25., (June 2004) R829-R858, ISSN 0953-8984.

Symposium N, ICMAT IUMRS 2005 3-8 July 2005, Singapore.

Symposium D, ICMAT 2009, 28 June -3 July, Singapore.

The $6^{\text {th }}$ International Workshop on Zinc Oxide and Related Materials, 5- 7 Aug 2010 in Changchun, China.

Wellings, J.S.; Chaure, N.B.; Heavens, S.N. \& Dhamadasa, I.M. (2008). Growth and characterisation of electrodeposited $\mathrm{ZnO}$ thin films. Thin solid films, 516., 12., (April 2008) 3893-3898, ISSN: 0040-6090.

Yang, Y.; Tay, B.K.; Sun, X.W.; Han, Z.J.; Shen, Z.X.; Lincoln, C.; \& Smith, T, (2008). Nanoelectronics Conference, INEC 20082 nd IEEE International, Nanyang Technical University, Singapore 24-27 March 2008.

Mitra, P.; Chatterjee, A.P. \& Maiti, H.S. (1998). Chemical deposition of ZnO films for gas sensors. J. Mater. Sci: Mat in Electronics., 9., 6., (December \& 1998) 441-445, ISSN: 0957-4522.

Ramamoorthy, K.; Arivanandhan, M.; Sankaranarayanan, K. \& Sanjeeviraja, C. (2004). Mater. Chem. Phys., 85., 2-3., (June \& 2004) 257-262, ISSN: 0254-0584.

Natsume, Y. \& Sakata, H. (2000). Zinc oxide films prepared by sol-gel spin-coating. Thin solid films., 372., 1-2., (September \& 2000) 30-36, ISSN: 0040-6090.

Chapparro, M.; Maffiotte, C.; Gutierrez, M.T. \& Herrero, J. (2003). Study of the spontaneous growth of $\mathrm{ZnO}$ thin films from aqueous solutions.Thin solid films., 431., 1., (May \& 2003) 373-377, ISSN: 0040-6090.

Water, W. \& Yan, Y- S. (2007). Characteristics of strontium-doped ZnO films on love wave filter applications. Thin solid films., 515., 17., (June \& 2007) 6992-6996, ISSN: 0040-6090.

Vijayan, T. A.; Chandramohan, R.; Valanarasu, S.; Thirumalai, J.; Venkateswaran, S.; Mahalingam, T. \& Srikumar, S.R. (2008). Optimization of growth conditions of $\mathrm{ZnO}$ nano thin films by chemical double dip technique. Sci. Tech. Adv. Mater., 9., 035007, ISSN: 1468-6996.

Vijayan, T. A.; Chandramohan, R.; Valanarasu, S.; Thirumalai, J.; Subramanian, S. P. (2008). Comparative investigation on nanocrystal structure, optical, and electrical properties of $\mathrm{ZnO}$ and $\mathrm{Sr}$-doped $\mathrm{ZnO}$ thin films using chemical bath deposition method. J. Mater. Sci., 43., 6., (March \& 2008) 1776-1782, ISSN: 0022-2461.

Chandramohan, R.; Thirumalai, J.; Vijayan, T. A.; ElhilVizhian, S.; Srikanth, S.; Valanarasu, S. \& Swaminathan, V. (2010). Nanocrystalline Mg Doped ZnO Dilute Magnetic Semiconductor Prepared by Chemical Route. Adv. Sci. Lett. 3., 3., (September \& 2010) 319-322, ISSN: 1936-6612. 
Saeed, T. \& Brien, P. O'. (1995). Deposition and characterisation of ZnO thin films grown by chemical bath deposition. Thin solid films., 271., 1-2., (December \& 1995) 35-38, ISSN: 0040-6090.

Cheng, H- C.; Chen, C- F.; Lee, C- C. Thin solid films., 498., 1-2., (March \& 2006) 1, ISSN: 0040-6090.

Sadrnezhaad, S.K. \& Vaezi, M.R. (2006). The effect of addition of Tiron as a surfactant on the microstructure of chemically deposited zinc oxide. Mat. Sci. Engg: B., 128., 1-3., (March \& 2006) 53-57, ISSN: 0921-5107.

Piticescu, R. R. Piticescu, R. M. \& Monty, C. J. (2006). Synthesis of Al-doped ZnO nanomaterials with controlled luminescence. J. Europ. Cer. Soc. 26., 14., (March \& 2006) 2979-2983, ISSN: 0955-2219.

H-M Zhou, D-Q Yi, Z- M Yu, L. Rang, Xiao, Jian Li, (2007). Preparation of aluminum doped zinc oxide films and the study of their microstructure, electrical and optical properties. Thin solid films., 515., 17., (June 2007) 6909-6914, ISSN: 0040-6090.

Joseph, B.; Manoj, P.K. \& Vaidyan, V.K. (2006). Studies on the structural, electrical and optical properties of Al-doped $\mathrm{ZnO}$ thin films prepared by chemical spray deposition. Ceramics International., 32., 5., (September \& 2005) 487-493, ISSN: 0272-8842.

Oral, A.Y.; Batisi, Z.B. \& Aslan, M.H. (2007). Microstructure and optical properties of nanocrystalline $\mathrm{ZnO}$ and $\mathrm{ZnO}$ :(Li or $\mathrm{Al}$ ) thin films. Appl. Sur. Sci. 253., 10., (March \& 2007) 4593-4598, ISSN: 0169-4332.

Peiro, A. M.; Ayllon, J. A.; Pearl, J.; Domenech, X. \& Domingo C. (2005). Microwave activated chemical bath deposition (MW-CBD) of zinc oxide: Influence of bath composition and substrate characteristics. J. Crystal. Growth., 285., 1-2., (November \&2005) 6-16, ISSN: 0022-0248.

Lokhande, B.J. \& Uplane, M.D. (2000). Structural, optical and electrical studies on spray deposited highly oriented ZnO films. Appl. Surf. Sci., 167., 3-4., (October \& 2000) 243-246, ISSN: 0169-4332.

Srinivasan, G. \& Kumar, J. (2006). Optical and structural characterisation of zinc oxide thin films prepared by sol-gel process. Cryst. Res. Technol. 41., 9., (September \& 2006) 893- 896, ISSN: 0232-1300.

Chou, T- L.; Ting, \& J- M. (2005). Deposition and characterization of a novel integrated ZnO nanorods/thin film structure. Thin solid films. 494., 1-2., (January \& 2006) 291-295, ISSN: 0040-6090.

Tang, Z.K.; Wang, G.K. L.; Yu, P.; Kawaraki, M.; Ohtomo, A.; Koinuma, H. \& Segawa, Y. (1998). Appl. Phys. Lett. 72., 3270, ISSN: 0003-6951.

Cracium, V.; Elders, J.; Gardeniers, J.G.E. \& Boyd, L. W. (1994). Appl. Phys. Lett., 65., 2963, ISSN: 0003-6951.

Look, D.C.; Reynolds, D.C.; W.Litton, C.; Jones, R.L.; Eason, D.B \& Cartwell, G. (2002). Appl. Phy. Lett., 81 1830, ISSN: 0003-6951.

Gorla, C.R.; Emanetoglu, N.W.; Liang, S.; Mayo, W.E.; Cu, Y.; Wraback, M. \& Shen, H. (1999). J. Appl. Phys., 85., 2602, ISSN 0021-8979.

Kotlyarchuk, B.; Sarchuk, V. \& Oszwaldowski, M. (2005). Preparation of undoped and indium doped $\mathrm{ZnO}$ thin films by pulsed laser deposition method. Cryst. Res. Technol., 40., 12., (December \& 2005) 1118- 1123, ISSN: 0232-1300. 


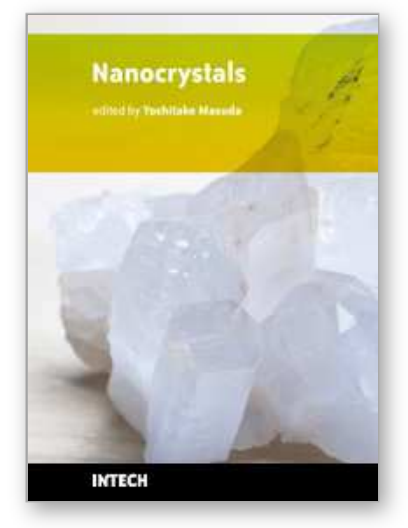

\author{
Nanocrystals \\ Edited by Yoshitake Masuda
}

ISBN 978-953-307-126-8

Hard cover, 326 pages

Publisher Sciyo

Published online 06, October, 2010

Published in print edition October, 2010

This book contains a number of latest research developments on nanocrystals. It is a promising new research area that has received a lot of attention in recent years. Here you will find interesting reports on cutting-edge science and technology related to synthesis, morphology control, self-assembly and application of nanocrystals. I hope that the book will lead to systematization of nanocrystal science, creation of new nanocrystal research field and further promotion of nanocrystal technology for the bright future of our children.

\title{
How to reference
}

In order to correctly reference this scholarly work, feel free to copy and paste the following:

Rathinam Chandramohan Pillai, Thirukonda Anandha Vijayan and Jagannathan Thirumalai (2010). Growth of Undoped and Metal Doped ZnO Nanostructures by Solution Growth, Nanocrystals, Yoshitake Masuda (Ed.), ISBN: 978-953-307-126-8, InTech, Available from: http://www.intechopen.com/books/nanocrystals/growth-ofundoped-and-metal-doped-zno-nanostructures-by-solution-growth

\section{INTECH}

open science | open minds

\section{InTech Europe}

University Campus STeP Ri

Slavka Krautzeka 83/A

51000 Rijeka, Croatia

Phone: +385 (51) 770447

Fax: +385 (51) 686166

www.intechopen.com

\section{InTech China}

Unit 405, Office Block, Hotel Equatorial Shanghai

No.65, Yan An Road (West), Shanghai, 200040, China

中国上海市延安西路65号上海国际贵都大饭店办公楼405单元

Phone: +86-21-62489820

Fax: $+86-21-62489821$ 
(C) 2010 The Author(s). Licensee IntechOpen. This chapter is distributed under the terms of the Creative Commons Attribution-NonCommercialShareAlike-3.0 License, which permits use, distribution and reproduction for non-commercial purposes, provided the original is properly cited and derivative works building on this content are distributed under the same license. 